\title{
¿La cuarta pared como lenguaje compositivo?
}

\author{
Carlos Emmanuel Brizuela Cabeza \\ Universidad Nacional de La Rioja, Argentina \\ charlie_94@hotmail.es
}

Fecha de recepción: 29/03/2019. Fecha de aceptación: 27/04/2019.

\begin{abstract}
Resumen
El presente trabajo corresponde a un recorte de la tesis de grado realizada por el autor para la Licenciatura en Arte Escénico de la Universidad Nacional de La Rioja, asesorado por la docente Daniela Martin (Universidad Nacional de Córdoba) en el año 2017. Consiste en la presentación de un bagaje teórico reflexivo destinado a echar luz sobre los modus operandi y posibilidades compositivas de la cuarta pared. En una primera parte nos enfocamos en los aportes de Denis Diderot, Bertolt Brecht y Augusto Boal en cuanto a la distancia teatral. Luego, exploramos y buscamos desmantelar palabras pertinentes a la discusión sobre la cuarta pared tales como convención, código, ficción y acontecimiento. Nuestra investigación procede paulatinamente desde la revisión de los componentes del acontecimiento teatral visto desde Jorge Dubatti, hasta poner la lupa sobre la tensión entre las perspectivas de quien produce escena y quien la percibe. Esta tensión deriva en reflexiones aplicables en la escena contemporánea capitalizadas como estrategias distanciantes y complicidades.
\end{abstract}

\section{The fourth wall as a Compositional Language?}

\begin{abstract}
This paper is a selected extract from the author's graduation thesis (Licenciatura en Arte Escénico, Universidad Nacional de La Rioja, 2017; supervised by Daniela Martin, Universidad Nacional de Córdoba). The essay presents a theorical framework that aims to help make visible the modusoperandi and compositional possibilities of the fourth wall. First, we focus on the contributions of Denis Diderot, Bertolt Brecht and Augusto Boal regarding the fourth wall. Then, we present a discussion of some related concepts, such as convention, code, fiction and event. Our study begins by reviewing some components of the theatrical event as defined by Jorge Dubatti and moves on to focus on the tensions generated between the perspectives of those who produce a theatrical event and those who are its spectators. These tensions lead us to some theorical ideas relevant to the contemporary scene which we define as distancing strategies and complicities.
\end{abstract}

Palabras clave

Cuarta pared-Distancia acontecimiento poestético distanciante complicidades

Keywords

Forth Wall- Distance Event Poesthetic Complicities 
$\mathrm{Al}$ pensar en la cuarta pared, hay que tomar en cuenta que es un sucediendo, un envoltorio de ficción que revela cuándo quiere y qué sucede en el encuentro de los que miran y son mirados. Me permito parafrasear a Pavis (1988), que define la cuarta pared señalando al espectador como un voyeur de la acción teatral, la cual se desarrolla independientemente de él a través de una supuesta pared que los separa (1988: 110). Por su parte, quienes interpretan dicha acción actúan como si esa pared estuviera realmente ahí, para llevar a cabo la ilusión de que no son vistos mientras lo son, y de que no están actuando para nadie cuando sí lo están. Podemos pensar esto en términos de dispositivo: José Sánchez y Esther Belvis (2015) se refieren al dispositivo como un espacio que relaciona elementos heterogéneos con otros, logrando gracias a las reglas y dinámicas propuestas desde el/los creador/es cierta autonomía por parte del dispositivo para funcionar en base a la interacción entre participantes y la lógica circunstancial propuesta. La cuarta pared determina reglas, fija su propia convención y es utilizada para tal fin; no sólo determina cierto tipo de actuación, sino también cierto tipo de espectador. A su vez, el investigador madrileño Óscar Cornago (2015) explica que los dispositivos artísticos proponen lógicas de relación a la vez que se denuncian como dispositivos, hacen evidentes las operaciones que llevan a cabo y se desenvuelven reinventándose a través de la exploración y puesta en juego de las reglas o instrucciones que ofrecen.

Podemos rastrear al teatro realista desde Constantin Stanislavski, director y teórico de teatro, quien a principios del siglo XX inició la búsqueda de un sistema de actuación que pueda ser usado como metodología para entenderla y cómo ésta debía crear una ilusión ante los espectadores. Para Stanislavski, la ficción más eficaz sugería que el actor debía dominar los recursos y herramientas de su cuerpo para provocar y sostener la ilusión; para ello también se recurre a la separación entre los actores y público donde la cuarta pared hace de límite tácito para que ambos mundos se desarrollen en sus respectivos espacios, el de los que son mirados y los que los miran. Hagamos énfasis en que estamos hablando de dos zonas de participación. El dispositivo de la cuarta pared consiste en el desarrollo de una ficción que se sostiene mientras quienes la producen no hagan contacto con el mundo no ficticio, es decir, que los actores hagan acto de omisión (o ignorancia, por qué no) del público, del otro mundo ajeno al que eligieron estar.

Por supuesto, nos encontramos con la primera contradicción: los actores y todo un equipo creativo involucrado en la producción de una obra de teatro que se presentan ante alguien para omitirlo, para hacer de cuenta que no está y, al mismo tiempo, para exponerse ante aquel ente invisible desde una distancia.

Desde Stanislavski hasta hoy, la ilusión y la distancia han sido puestas en jaque reiteradas veces por parte las vanguardias y lo que conocemos como el arte moderno y posmoderno. Pero nos alejaremos por ahora de la idea de ilusión para preguntarnos qué pasa con la distancia.

\section{Distancias}

¿Qué pasa con la distancia en una manifestación que consta de la reunión de obra y espectador?

\section{Distancia diderotiana}

El escritor y filósofo francés Denis Diderot, autor de libros como La paradoja del comediante (1769), es quien nos abre la puerta a la distancia. Buscando teorizar sobre la escena en 1758, Diderot relaciona al teatro con el cuadro pictórico a través 
de observaciones estéticas. Sobre el autor, nos interesa particularmente la mirada

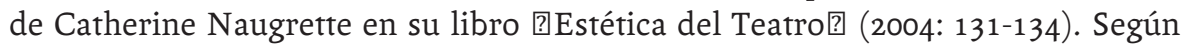
la autora, Diderot piensa el cuadro pictórico como un instante elegido para provocar placer a través de la intervención del pintor. Para él, la acción que ejerce el artista al capturar un instante de la realidad es también un acto de condensación de la misma bajo el criterio de ser considerada bella. Desde esta noción, el cuadro pictórico se destaca por aislar del mundo cotidiano la visión del artista sobre el mismo. Esto es de vital importancia para el filósofo, porque así sostiene que para tener una experiencia estética es necesario que la obra se diferencie de la realidad a la que representa, que se destaque entre la normalidad y se mantenga hermético para así provocar placer.

La relación del cuadro pictórico con el teatro es pensada a partir de que ambos son representaciones de la realidad en una época donde la fotografía todavía no existía. Por esto es que la escena también es pensada como cuadro, ya que para Diderot es importante que se mantenga una distancia, una clausura de la obra al espectador o la restricción adecuada para experimentar el placer desde la contemplación voyerista. Si recordamos la contradicción por omisión de la que hablamos antes, podemos considerar la escena teatral como una muestra de realidad que debe omitir al público para garantizarle su existencia, pues no se niega a quién no está ahí, sino a quien pretendemos que no lo está.

La realidad cotidiana contempla, opina, no percibe la obra, sino la perspectiva condensada en ella del mundo en el que el espectador habita; es decir, la obra se vuelve un espejo, un reflejo distorsionado y manipulado por el artista. De hecho, en este sentido, estamos de acuerdo con Jacques Rancière quien sostiene que:

(...) Lo que el hombre contempla en el espectáculo es la actividad que le ha sido hurtada, es su propia esencia, devenida extranjera, vuelta contra él, organizadora de un mundo colectivo cuya realidad es la de este desposeimiento (2010: 14).

En síntesis, el lugar de la distancia diderotiana se efectúa desde la delimitación de dos mundos distintos: el que se encierra en la obra (una perspectiva artística) y el que contiene a la obra (realidad cotidiana).

\section{Distancia brechtiana}

Para coincidir con otra visión de la distancia tenemos que ubicarnos en una Alemania testigo de grandes cambios paradigmáticos. El impacto del comunismo, el papel del obrero frente a la burguesía, el paso de la Primera Guerra mundial y el camino hacia la segunda influyeron de manera contundente el trabajo de escritura, dramaturgia y dirección de Bertolt Brecht. La visión que Brecht proyectaba en sus obras de teatro es denominada por él mismo como Teatro Épico, un tipo de teatro dirigido no hacia un público, sino a los ciudadanos alemanes que componían ese público.

El corazón del Teatro Épico se encuentra en lo que Brecht llama distanciamiento: una búsqueda por suprimir la posibilidad de que el espectador se sienta identificado o conmovido por la obra teatral a través de recursos estilísticos que derriban, suspenden u omiten la ficción (mediante la fábula, la interpelación de los actores hacia el público, carteles que adelantan la acción a suceder en la escena, canciones y cambios escenográficos a la vista del espectador, etc) (Ubersfeld, 2002:40). Este distanciamiento se ejecuta para deshabilitar y rehabilitar los lugares de conexión entre el mundo de la obra y el cotidiano, una manera de desarmar la ilusión para hacer del teatro un medio político; un arte político. 
En Brecht, vemos a Alemania, a las organizaciones de izquierda y las tensiones existentes entre burgueses y obreros. Es en el distanciamiento donde Brecht deposita su confianza, la confianza de que un espectador obrero y trabajador se encuentre con las ideas que el director considera que le hacen falta. Cree que derribando esas cortinas ficticias, esa cuarta pared, que hablándole de frente con la excusa de ser parte de una obra de teatro el espectador puede apreciar el contenido y entender lo que la pieza transmite, entender desde una razón cotidiana y no desde la catártica belleza mimética. La hipótesis del director alemán sería comprobada cuando el obrero, fuera del teatro, contagiado con una responsabilidad ciudadana con ánimos de revelación y revolución, se vea a sí mismo con necesidad de cambiar la realidad en la que se encuentra, de modificar su cotidianidad, siendo consciente de su papel en el mundo y las posibilidades del mismo.

Observamos aquí la diferencia que separa la distancia diderotiana de la brechtiana: Brecht elige no omitir a su espectador, sus obras lo incluyen y necesitan, buscan sobrevivir más allá de sí mismas en intenciones y comportamientos. Aquel distanciamiento omite la ficción, no al espectador. La cuarta pared se convierte en una bisagra que no clausura la ficción, sino que la suspende y flexibiliza para comunicar el mundo interno de la obra con el externo; ya no es la obra desarrollándose enajenando al espectador para exhibírsele, sino que le habla directamente, inclusive de él como sujeto, se le proyecta desde el marco de la ilusión para jugar con el mismo; la tensión se vuelve distinta; ya no escribo sobre algo que estoy investigando, escribo para que vos me leas, lector/a.

\section{Distancia boalista}

La última distancia de este capítulo ya no es europea, sino latinoamericana. Las líneas artísticas de Brecht tendrían sus discípulos y redirecciones, viajes y aterrizajes. El caso que nos interesa se encuentra en Brasil a mediados de los años 60, en las prácticas de un dramaturgo y director llamado Augusto Boal.

Los intereses de Boal se ubican entre dos herencias bien definidas. Por un lado tenemos las incursiones realizadas por Brecht y, por el otro, las teorías que Paulo Freire describe en su libro Pedagogía del Oprimido (1968). Augusto Boal transporta las ideas de Freire a lo que se concibe hoy como Teatro del Oprimido, un sistema de teatro pedagógico que se trata de y para las clases oprimidas con la función de fomentar el pensamiento crítico y la lucha contra las clases opresoras. Este teatro varía del concepto brechtiano al involucrar el carácter de la opresión como problema social (heredado directamente de Freire), en un acto metafórico de toma de armas para combatirla y generar así un cambio cultural.

El Teatro del Oprimido busca involucrar al espectador no sólo como sujeto, sino como actuante. De hecho, una de las formas de este teatro que más se conocen es el Teatro Foro. En el Teatro Foro, los actores y el equipo de trabajo creativo presentan una obra teatral, cuyo conflicto conste en un problema social particular y cotidiano (a veces doméstico); una vez que la obra llega al punto de desarrollo de dicho conflicto, ésta se detiene para invitar a personas dispuestas en el público que tomen el lugar de los actores e intenten resolverlo apelando a los valores ciudadanos para así, fomentar las soluciones prácticas a las desigualdades que se exhiben para con sus equivalentes en el mundo cotidiano.

Otro ejemplo que nos interesa es el desarrollo del Teatro Invisible, especialmente por su tratamiento de la distancia. Al igual que en el Teatro Foro, en esta propuesta los actores presentan una situación de opresión o injusticia cotidiana para el común del público presente, aunque la diferencia, en este caso abismal, consta en el entorno 
de esta ficción. El Teatro Invisible está pensado para desarrollarse en lugares poco convencionales (si hablamos de teatro); fuera de la caja italiana, las obras de este tipo de teatro suceden frente a transeúntes en lugares públicos, donde los espectadores son simplemente la gente que se encuentra ocasionalmente ahí. La distancia se hace niebla cuando tomamos en cuenta que en obras de este tipo de teatro, nunca se devela que los que actúan están actuando y para la gente que interviene, opina o presencia los conflictos preparados, estos se toman como eventos ocasionales de una cotidianeidad.

Aquí, la distancia teatral diderotiana ha sido removida en su totalidad; el ritual de posicionarse ordenadamente en sillas frente a un escenario habitado por actores conoo como aquel individuo compositivo que completa la experiencia al involucrarse como sujeto y objeto, es decir, ya no sólo es espectador sino actor (o como Boal lo define, espectactor).

\section{Pactos que Comunican}

\section{Convención}

Recordar. Acordar. Convenir. Volvemos por un momento a Patrice Pavis sobre la convención:

Conjunto de presupuestos ideológicos y estéticos, explícitos o implícitos, que permiten que el espectador reciba correctamente la representación; "acuerdo" establecido entre autor y público según el cual el primero compone y escenifica su obra según normas conocidas y aceptadas por el segundo (1988: 97 - 98).

Desde la idea del acuerdo podemos pensar la convención como el convenir y, a veces, como un convencer. El convenir es tanto el negociar como su aceptación; en teatro, no hay mucha negociación hacia el espectador. De hecho, existe el ofrecimiento de un convenio no negociable, en el sentido de que al espectador se le disponen ciertos términos estéticos ficticio-legales con los cuales opera una obra de teatro (y/o de arte), que a su vez no puede modificarlos a menos que aquellos términos establezcan que así sea, (en cuyo caso, la disposición de términos editables también se convierten en la norma). En definitiva, aquel convenio opera a conveniencia de la poética que lo propone y, en este punto, es cuando surge la ligera desviación del concepto. El espectador sabe y tiene naturalizado que el acuerdo escénico consta de recibir la obra como a ésta le conviene, ya que en cierto sentido, se deja convencer por los términos que usa a su favor.

\section{Convención > Código}

Al hablar de convención nos parece pertinente destacar el acto de la lectura, el entendimiento de aquel acuerdo que absuelve y habilita mundos. Anne Ubersfeld describe la convención desde un renglón muy singular: "CONVENCIÓN > CÓDIGO" (2002; 28), lo cual nos fuerza a redirigidos (al menos de manera muy superficial) a hablar de código.

Un código es un conjunto de normas que une un sistema de signos para permitir la recepción del mensaje (Ubersfeld, 2002: 23).

La diferencia sutil entre convención y código: el primero funciona gracias al segundo. O eso podemos pensar, ya que la convención es un tipo de código de entre los muchos y diversos que el teatro es capaz de aglutinar. Los códigos de comunicación son lenguaje, se leen y conectan un mensaje con el entendimiento del mismo por parte de quien lo recibe. Por eso es que importa mencionarlo si hablamos de cuarta 
pared, ya que ésta separa el mundo cotidiano del escénico y la lectura que codifica esta operación por parte del espectador es la victoria del código y el hecho de mantenerla vigente (de principio a fin del espectáculo) es una convención.

\section{Algo de ficción}

Según Pavis (1988: 220), la ficción es una forma discursiva que hace referencia a elementos reales, pero que existen en la imaginación de autores, lectores y espectadores. Bajo esta definición podemos relacionar la ficción como la decodificación de las sustituciones (a elementos de la realidad) que la obra ofrece, el resultado de leer las formas. Entonces, si la ficción durante la escena es el resultado de la lectura, del desarme de nudos vueltos código, de la relación que aflora en cada voyeur con las formas dispuestas y preparadas para él o ella, la ficción existe mientras esa relación dependiente (lector/lectura) se mantenga constante.

Si bien hablar de ficción puede tomarnos todo un capítulo y hasta libros enteros, nos interesa destacar algo en relación a lo visto anteriormente. Búsquedas como las de Brecht y Boal, interrumpen o suspenden la ficción en pos del desarrollo de sus estéticas, cada cual busca aprovechar aquella no ficción para determinados fines, desatando así mismo, otros códigos y convenciones. Ambos ubicaron al espectador en un lugar completista, donde él debe terminar el mensaje que le transmiten las obras, pero ese ya no es lugar de la ficción, es su intención de perseverar y de ofrecer un residuo post-escena que no terminara en un recuerdo. En cierto sentido, estas búsquedas alimentadas con la ruptura de la cuarta pared se preparan para darle valor al hecho de presenciarlas como espectador, al acontecimiento.

También podemos afirmar que la ficción funciona como la comunicación de pasado con presente, lo ya hecho y su atestiguación. Este recorrido lineal con convención (que funciona a través de), código(s) y (con el fin de sostener una) ficción para tiene carácter virtual, es parte de un tránsito que corresponde al intelecto del espectador, el decodificar, entender, leer, disponerse, asimilar, atestiguar; pero asimismo es un ejercicio que sucede en el tiempo y lugar en el que transcurre un acontecimiento.

\section{Lo que Sucede}

En Introducción a los estudios teatrales, Jorge Dubatti propone pensar al teatro como un acontecimiento, un ente que surge como producto de un acontecimiento ontológico $\mathrm{y}$, de hecho, nos guía a conversaciones familiares sobre nuestro objeto de estudio:

Si théatron (en griego) reenvía a la idea de mirador, la raíz compartida con el verbo theáomai remite al ver aparecer: el teatro, como acontecimiento, es un mirador en el que se ven aparecer entes poéticos efímeros, de entidad compleja (2011:34).

Así, Dubatti abre la puerta para diseccionar el acontecimiento teatral fragmentándolo en tres subacontecimientos: convivio, poiesis y espectación.

Al hablar del convivio, el autor lo define como una reunión de cuerpos presentes con otros cuerpos presentes que transcurre en y durante una unidad cronotópica de territorio y momento temporal. Este encuentro de presencias humanas sin intervención de medios tecnológicos o des-auráticos distinguen al teatro y a las artes escénicas (como la danza, la performance y el happening) de las otras manifestaciones artísticas que no dependen de alguien que las presencie para existir. Aclararamos que esto sucede en el sentido de que las obras escénicas se preparan para una reunión convivial desarrollándose y extinguiéndose en ella, diferente a imágenes virtualizables, textos reimprimibles y canciones grabadas. 
El autor hace lugar entre sus párrafos para hablar de la compañía como una fuerza de combustión del hecho teatral donde se involucra el respeto, la paciencia y la fraternidad como conductas apropiadas de espectadores para con los actores y viceversa. Es en este lugar, donde todavía abundan los modales, que las convenciones y códigos pueden dejarse surgir como se planean porque no son eternos.

El convivio nos plantea el encuentro, la reunión, pero hay que continuar explicando los subacontecimientos dubattianos para entender quiénes o qué se encuentran y reúnen:

Dentro del convivio y a partir de una necesaria división del trabajo, se producen los otros dos subacontecimientos, correlativamente: un sector de los asistentes al convivio comienza a producir poíesis con su cuerpo a través de acciones físicas y físico-verbales, en interacción con luces, sonidos, objetos, etcétera; mientras, otro sector comienza a expectar esa producción de poíesis. Se trata respectivamente del acontecimiento poiético y del acontecimiento de expectación (2011: 37).

El acontecimiento poiético es explicado como un nuevo ente producido y conformado por la acción corporal, es decir, un ente alejado del mundo cotidiano sostenido por un cuerpo poético (que se comporta de manera singular). El autor explica que ante la herencia aristotélica de considerar poesía a la fabricación (manufacturada) de un objeto artístico (aquel cuerpo poético material y elaborado a través del ser humano), prefiere sumar este sentido al que concibe poiesis como fenómeno, por lo que considera al ente poético como el acto de hacer un producto artístico y al producto en sí mismo.

La expectación es tomada como un acto de conciencia (que oscila entre ser relativa o intuitiva) de la existencia del ente poético como comportamiento individual y singular corrido de cotidianidad. Dubatti explica que ese acto de conciencia es la distancia ontológica que se requiere para ser espectador, más allá de las interferencias o provocaciones que esa distancia posea (como ya vimos con Brecht y Boal). Por ahora dejaremos este tópico para retomarlo con otra mirada más adelante.

\section{Entre Individuos}

\section{Cualidad poestética}

En Volverse Público. Las transformaciones del arte en el ágora contemporánea (2014), Boris Groys desarrolla un conjunto de ensayos sobre los aspectos del arte que han mutado desde la modernidad, introduciéndonos desde una diferencia: aquella distancia entre estética y poética. Groys asocia la estética a la perspectiva y experiencia del espectador frente a la obra de arte, la cual lo afecta al generarle una (tan popularmente llamada) experiencia estética o antiestética (de placer o displacer). Por otra parte, habla de que la poética es la perspectiva y producción de quien hace y piensa el arte como poesía y como técnica, lugares donde Dubatti ubica la poíesis.

Resumiendo, lo que hemos hablado anteriormente sobre acontecimiento virtual (es decir, la cadena entre convencion-código-ficción) y el sub-acontecimiento de la expectación (por parte de Dubatti), son análisis afines a una perspectiva estética. El detalle se encuentra en que al hablar desde la estética elegimos posicionarnos de una manera distante del objeto de arte, mientras que si hablamos de poética o - en términos más coherentes a este texto - de poesía, la distancia se toma en relación al espectador. Por supuesto, estos alejamientos poseen la función de especificar la mirada, porque sino inevitablemente volvemos a pensar sobre el espectador desde la producción de arte o pensar en la obra desde un espectador. 
Nos animamos a suponer: la división de productores de poesía y experimentadores estéticos no sería del todo una oposición ni mucho menos una separación. El producir escena conlleva una serie de decisiones y recursos que se toman en cuenta para componer el cómo (no tan indistintamente del que). Esas elecciones afectan, independientemente del grado de su intención, las experiencias estéticas del público, por lo que el modo de producir se convierte, a modo de ecos y reverberaciones en las interpretaciones durante y posteriores a la exposición convivial, es decir, decidir el cómo también es la repercusión de ese cómo.

Al pensar en los cómo de la producción escénica, nuestro aporte consiste en abordar la cuarta pared como (algo muy cercano a) un lenguaje donde sucede la transmutación de poética en estética. La tensión que genera la cuarta pared puede ser pensada como mecanismo poestético, en el sentido de que la cuarta pared hace presente una confluencia y devenir de lo producido vuelto interpretación, recursos desencadenantes de experiencias cumpliendo su destino de volverse otro en otros, la metamorfosis ocurriendo en el convivio de participantes cercanamente distantes y públicamente íntimos. Bajo esta idea le atribuimos la cualidad poestética a la cuarta pared debido a que es en ella que el modo de producción (proceso y producto poético) se vuelve interpretación (experiencia estética). Al tener en cuenta que los procesos de creación determinan sistemas de lenguaje, de actuación, de exposición y comunicación que la escena mantendrá con quien la expecta a futuro, podríamos estar hablando de estrategias distanciantes.

Proponemos llamarle poestética al evento que sucede desde las vísceras de la cuarta pared, porque el énfasis está en la transformación de aquella exposición de una propuesta escénica en una lectura y decodificación de aquellas estrategias compositivas hechas y planeadas para acontecer; así mismo, elegimos denominarlas distanciantes porque consideramos que ese es el efecto que escénico que poseen.

Al utilizar la palabra poestética nos es necesario mencionar que el escritor español Alfonso Sastre (2010:14.) ya habló de ella desde una perspectiva diferente a la nuestra. Sastre utiliza poestética para hacer énfasis en la perspectiva de la praxis poética sobre la estética y, a su vez, llama estetopoética al caso invertido. No obstante, preferimos aferrarnos a considerar la poestética como la mutación de la producción y el producto consumiéndose en interpretaciones de espectador; en la tensión de elementos que se escriben a la misma velocidad que son leídos y efimerizados en la escena.

Ante todo, no podemos continuar sin hacer un pequeño comentario sobre las reflexiones que el teórico Nicolás Bourriaud denomina como estética relacional (2006). La estética relacional corresponde a una teoría de la forma que abarca las propuestas artísticas que se exponen al contacto con el espectador de manera interactiva, haciendo énfasis en la relación que la obra tiene con el espectador y viceversa. El arte relacional pone la lupa sobre la forma del encuentro, la duración del mismo, lo que puede suceder en él, las posibilidades artístico-sociales capaces de surgir de la relación entre individuos presentes y obra. Para el arte relacional, el valor de la obra no se determina por la obra en sí como objeto/producto, sino por su manera de proponerse a ser habitada, escrita o modificada por el espectador para completar su status de obra de arte; las poéticas de estas obras se concentran no en un contenido a transmitir, sino a la relación y experiencia que el espectador pueda tener con ellas, les interesa abrir la brecha comunicacional a lugares en los que existe un universo en común que ya no responda a las relaciones convencionales entre espectador y objeto de arte. Nosotros pensamos que esta perspectiva puede sernos útil antes de hacer función y no durante el acontecimiento solamente. 


\section{Estrategias distanciantes y complicidades}

\section{Estrategias Distanciantes}

Al pensar en los modos de relación con el espectador que la obra tiene a disposición y elección, es que nos preguntamos si es posible categorizar las sensaciones que la escena es capaz de brindar a través de los sentidos de los espectadores. Para ello, proponemos ciertas estrategias distanciantes: como procedimientos compositivos que se eligen en calidad de la propuesta escénica y los cuales devendrán en determinada reacción de parte del público. No hay que entender esto como una imposición a pensar que al crear escena se debe tener en cuenta sí o sí en cómo se está proponiendo esa creación al espectador, sino ser consciente y conocer las variables que pueden aportar o no a la creatividad y al producto escénico, considerando las formas que el acontecimiento deja al descubierto en pos de las intenciones creativas que se tengan.

Percibimos que, para irrumpir y discutir la cuarta pared, es necesario planear escenas que se involucren con el espectador a través de sus sentidos, estimulándolos y contando con sus cuerpos en el espacio. Por supuesto, esto se trata de un cómo, y el para qué se traduce en generar distancia.

A continuación, proponemos una categorización a los grados de relación que pueden existir entre espectador y escena bajo el nombre de lo que ya nombramos como estrategias distanciantes:

\section{Grado o}

Es el aura, los cómplices. El grado o es la reunión en convivio como tal, la presencia viva de hacedores y espectadores en un mismo lugar; vida presente ante vida presente, donde no sucede nada más que existir para existirle a la escena.

\section{Aire / Sobre la vista}

Sólo mirar: la distancia que genera la mirada inicia con la cuarta pared por sí misma. Acá vemos a la escena haciendo acto de omisión total de los espectadores que aún presentes, totalmente enajenados del mundo propio de la escena que presencian.

Cruce de mirares: los ojos que miran desde adentro hacia afuera de la escena, la conexión interpersonal que hace al espectador parte de aquel mundo que se percató de su existencia. Cuando un intérprete mira al espectador es en realidad la escena quien lo mira, es la tensión sostenida desde el otorgarle vida a aquél que bajo la oscuridad, no la tenía. La pared se rompe con una simple mirada.

Sin mirada: el anular el sentido de la vista del espectador es una dinámica empleada por lo que se conoce generalmente como Teatro Ciego. Esta propuesta hace necesario que el espectador perciba la escena desde sus otros sentidos, siendo necesaria la ejecución de ciertas dinámicas sonoras, olfativas o de movilidad para lograr la interacción con el público.

\section{Eco / Sobre el oído}

Diálogos e ideas: esta estrategia se basa en la escucha, escuchar lo que la escena dice. En la convención de la cuarta pared, existe el empleo de un lenguaje escénico interno y hermético que se limita a anunciar diálogos entre quienes interpretan, expresar en voz alta los pensamientos de los individuos escénicos y los sonidos que entren en función de la lógica de lo que sucede. Dicho desde una puesta realista, los sonidos y 
las voces se desenvuelven en un entendimiento consecutivo interno que funciona para sí mismos dentro y para la escena, donde los actores se hablan sólo entre sí y para sí.

Narración: en la narración el lenguaje se torna enunciación. A diferencia de lo que conocemos como diálogos o conversaciones la narración encuentra dos variantes: por un lado, la explicación de la obra para sí misma, donde la obra necesita contextualizarse o hablarse a sí misma de una manera introspectiva, casi como el ítem anterior con la diferencia de que se usa la enunciación explicativa (o narrativa) sin destinatario claro. La otra variante es una narración externa, que se expresa hacia fuera de la escena buscando más bien una comunicación sólo de ida con alguien (espectador) que posiblemente esté ahí para escucharla. Esta segunda variante podemos considerarla como una búsqueda de complicidad que a su vez mantiene sus propias reglas para generarla.

Interrogación y demanda: son aquellas palabras que se dirigen directamente al espectador y le hablan, ya sea mirándolo a los ojos o simplemente haciéndolo presente a través de palabras que le exigen una respuesta, que lo enfrentan y lo incorporan atentando contra la distancia de omisión. Como ejemplo podemos pensar en los shows de stand up, obras de teatro infantiles o shows de improvisación.

\section{Nervios / Sobre el tacto}

El modo en que la escena toca al público varía entre pasivo y activo. Un modo pasivo es cuando la escena salpica objetos al espectador, objetos como papel picado, humo o cosas que no le requieran más que quedarse quieto donde está. El modo activo se denuncia en aquellos objetos o acciones que son recibidas e incorporadas por el espectador, es decir, que participa mediante el sostenimiento o disposición física de su cuerpo para con una escena que le entrega algo, pudiendo ser un vaso con agua, una prenda de ropa para que éste sostenga, un avión de papel que se esfuerce por alcanzar o, en definitiva, cualquier objeto que le modifique la posición parcial de su cuerpo.

\section{Destierro / Sobre la Orientación I}

Siguiendo una lógica progresiva, otra manera de relación con el público es la modificación en el espacio que éste ocupa. Su modificación en el espacio puede ser para la escena y por la escena. La modificación por la escena tiene que ver con un cuerpo poético que se desarrolla a través del público, es decir, que recorre el espacio del acontecimiento haciendo o provocando que el espectador se mueva (deba darse la vuelta, dar paso a alguien o cambiar de posición en el espacio). En este caso, el cambio de lugar se da con la irrupción de una escena que se antepone y provoca la modificación espacial del espectador.

En la modificación espacial para la escena sucede un cambio de posición de parte del espectador en disposición del cuerpo poético; para que la escena siga ocurriendo quien expecta debe modificar su lugar en el espacio como un acto voluntario para una escena que lo invita a hacerlo, que lo invoca en lugar de provocarlo.

\section{Síntoma / Sobre la Orientación II}

A esta estrategia la podemos considerar como una demanda propia del happening, de la performance, o de las instalaciones artísticas diseñadas para funcionar desde la interacción con el espectador. La orientación a ejecutar una acción determinada por la escena se entiende como producto de una necesidad dramática y dramatúrgica, o sea, le es necesario a la escena que quien inter-actúa con ella se involucre a un nivel de respuesta activo y preciso a través de una acción particular. 


\section{Indiferencia / Sobre el Final (de la distancia)}

Quizás la coincidencia corresponda a otro equivalente para el acontecer. Hasta ahora hablamos sobre distancias donde espectadores e intérpretes reunidos se diferencian (y separan) entre sí, perpetuando con el distinguir aquella distancia que la cuarta pared ya se encarga de hacer presente. Pero, ¿es posible una coincidencia que remueva ese distinguir, tanto de escena como de participantes, lugar y momento? Utópicamente visualizamos un estado en el que no hay roles que separen, sino un evento que los haga uno, una coincidencia perfecta que tal vez, podamos buscar a través de jugar a ser cómplices.

\section{Complicidades}

Desde que hablamos sobre las distancias, este escrito en su totalidad se ha esmerado por entender la riqueza de la cuarta pared a la hora de componer escena. Incluso atravesamos el punto de partida de pensar la comunicación de escena con espectador a través de los sentidos que dio como resultado una categorización de lo que traducimos y proponemos como estrategias distanciantes. En borradores, el componente que ha estado ahí desde las distancias sin hacerle énfasis es la complicidad. Es difícil hablar de la complicidad sin hablar de la distancia, porque el teatro hace cómplice a quien lo perciba, sea participante activo como lo proponía Boal o voyeur pasivo como lo sugería la distancia diderotiana. ¿Será la complicidad lo que realmente importa al hablar de la cuarta pared?

La Real Academia Española posee más definiciones para cómplice que para complicidad, por lo que nos proponemos una definición que aglutine lo referido a cómplice y que sea de utilidad para nuestra investigación. Vamos a pensar la complicidad como la manifestación de un acto de cooperación y participación que asocia a sus participantes entre sí. Ser cómplice en el teatro se vuelve imprescindible si recordamos que el lugar del espectador es constantemente cómplice de un acto teatral.

Pensemos que, en el teatro, ser cómplice, o mejor dicho, hacer cómplices es jugar con la distancia, considerar las sutilezas y hacer constantes guiños. La cuarta pared, como convención y como elemento que hace distinguir los cuerpos que actúan de los que los ven, genera como tal un tipo de complicidad primaria a base del juego de que los espectadores no están ahí cuando realmente sí lo están (e incluso, son la razón de existir de aquella escena). Pero, cuando la cuarta pared se irrumpe (cuando aquella ilusión se sale de sí misma), las posibilidades en cuanto a la complicidad se multiplican, los mundos de los que miran y son mirados se desnudan y contemplan entre sí en una tensión a lo feedback: con espectadores que miran a actores que les demuestran a los primeros que saben que están siendo mirados.

La verdadera hipótesis surge acá, en el develar más lugares para hacer cómplices, más bisagras para la ilusión, fisuras en las convenciones y/o distancias estratégicas. La complicidad hace posible al espectador habitar la ficción, ser parte de un nuevo plan, jugar durante una pequeña porción de tiempo a modificar su propia convención de espectador pasivo. Una vez más proponemos categorías con la intención de sujetarlas a una lógica de funcionamiento. A continuación, complicidades:

1. Complicidad Primaria: la imprescindible; aquella complicidad que se genera con la sola presencia del espectador como inaugurador del convivio, la otra mitad de la reunión. En este caso, encontramos la distancia diderotiana nuevamente, la que necesita al contemplador como tal donde la cuarta pared actúa en su forma más pura. 
2. Complicidad Visual: donde la escena hace explícito su conocimiento de que está siendo expuesta y contemplada ante otros seres. Pues el contacto visual, de mirada a mirada entre escena (actor) y público (espectador) es aquel guiño que nace de un sentido de la vista a otro, el percatarse (a propósito y notablemente) del individuo que nos está viendo del otro lado del mundo ficticio, es un paso a una complicidad menos clausurante del espectador como sujeto presente.

3. Complicidad Discursiva: consideremos al discurso como un provocador sutil de complicidad. A través de la palabra se puede hacer referencias a personas, lugares y eventos reales que dependen mucho de la zona geográfica y el momento en que se esté representando. Creemos en la palabra como generadora de una complicidad muy relativa (tanto como todas), capaz de evocar una conexión del mundo ficticio con el cotidiano o real a través de un dato particular que sea mencionado. Por ejemplo, una obra de teatro que en mayor o menor medida enuncie a través de una voz las palabras incidente de Cromañón, generaría cierta complicidad en quienes conocen acerca de este hecho puntual que ha marcado la historia de Argentina en los últimos quince años y que, probablemente, espectadores de otra nacionalidad o lo suficientemente jóvenes que desconozcan el acontecimiento del 30 de diciembre del 2004 en aquel barrio (Once) de la Ciudad de Buenos Aires no compartan la complicidad que otros comparten. A través de la palabra, la escena también puede dejar en evidencia información (compartiendo o usándola) que se corresponde con la del mundo cotidiano. Por esto es que las obras ilustrativas de un acontecimiento particular de conocimiento común para el contexto en que se la representa (hechos históricos, problemas sociales latentes y sobreexpuestos), juegan con la complicidad en el sentido de que todos saben de qué se trata; y dicho sea de paso, acá se encuentra una de las grandes dificultades a la hora de representarlas, ya que el exceso de complicidad corre peligro de interferir con el compromiso poético presente en el contenido de la ficción. Dicho de otro modo, mientras más grande sea el campo ganado por el contenido (digamos Hamlet), más difícil es hacerlo interesante, porque el exceso de datos compartidos entre escena y espectador hace necesario el colorido poético, el toque particular que el teatro entendido como juego es capaz de conceder.

4. Complicidad Dirigida: tomemos de ejemplo los shows de títeres o de clown, en la interacción con el público en busca de su participación y sus respuestas. Pensemos en el acto de responder a la escena, de involucrar la palabra, asentir, negar, saciar la necesidad que tiene la escena de esa misma respuesta. Algunas de estas puestas en escena dirigen la respuesta del público a responder como se le indica, es decir, plantan las bases para que el público responda de la forma que la obra necesita que hagan sin variantes que la puedan hacer mutar o perder la coherencia. Desde este punto de vista, espectáculos como el stand up aprovechan este tipo de recursos para crear complicidad con un público que necesita de la misma para sostener su propio discurso. Esta complicidad está contemplada; la participación del público se habilita en pos de la reivindicación de la verdad de la escena en el sentido de que las respuestas corporales del público sólo pueden ser las que la escena les brinda a responder.

5. Complicidad Dramatúrgica: A diferencia de la Complicidad Dirigida, esta complicidad no aparenta su aporte de escritura, sino que verdaderamente a través de la participación del espectador la escena se escribe, se modifica, pero ya no el sentido de que el espectador hace al teatro acompañando a los actores, sino que realmente sin su participación, la escena no se resuelve, 
no sucede ni se puede ensayar. Un ejemplo muy al caso son los shows de improvisación donde el público tiene la palabra, puede elegir involucrarse, dar ejemplos, ideas, aportes y la escena aprovecha estas intervenciones para escribirse total o parcialmente.

6. Complicidad Performática: a estas alturas, hay que reconocer que el teatro es un juego de complicidades operando, además del hecho de que para que exista drama es suficiente con que exista una complicidad primaria (ya explicada), dando por conclusión que toda complicidad es dramática. Consideramos que es necesaria otra denominación donde podamos ubicar los happenings y el Teatro Foro de Augusto Boal. ¿Qué sucede en casos así en los que la escena de una manera direccionada abre las posibilidades a la escritura por parte del espectador de una manera más volátil? O mejor, ¿el espectador puede hacer dramaturgia sin hacer el drama? La sutil diferencia entre dirigir la participación y dirigir hacia la participación. Ciertas prácticas performáticas (y sobre todo los happening) buscan muy a propósito exponerse al azar, al evento aleatorio y a lo inesperado; de hecho, ahí se encuentra la riqueza de estas propuestas. Pero ¿qué las diferencia de lo que ya denominamos como complicidad dramatúrgica? Las pistas nos muestran que el factor riesgo que provoca el azar como aporte poético desde la participación del público lleva la complicidad dramatúrgica un poco más allá. La Complicidad Performática es esa otra denominación que juega con el azar que la escena es capaz de permitirse, donde caben las desviaciones, se hacen malabares con las propuestas y la ficción se vea frágil.

7. Variante Metateatral: independientemente de cómo se la ejecute (con palabras, a través de acciones, uso de luces, etc.), las propuestas escénicas donde la escena da a entender su condición de escena como tal y se desarrolla a través de este entendimiento, hablan de una variante que también se da en la televisión y el cine ("Deadpool", 2016). Pensemos en obras sobre obras, en teatro que habla sobre teatro, en la mutilación de los artificios que componen la escena para, justamente, mostrar sus fibras internas, desnudar el gran dispositivo y hacer radiografía de sus engranajes y hasta mofarse de la marca de aceite que usa. Por supuesto que poéticas de éste estilo se proponen hacer entrar en discusión al teatro consigo mismo desde y para sus participantes. Para dar un ejemplo: la performance "The Artist is Present" (MoMA, 2010) de Marina Abramovic, que consistía en ella sentándose en un atril del Museum of Modern Art sin moverse desde que éste abría hasta que cerraba. La performance invitaba a repensar la presencia del cuerpo del artista en lugar del cuerpo del objeto. "The Artist is Present" muestra a una persona como objeto de museo y al mismo tiempo deja expuesta la esterilidad y característica mortuoria del objeto de museo, haciéndola coexistir con la presencia de un individuo que se somete durante las horas de una jornada de trabajo al mismo tratamiento que se les da a las demás obras de arte. Como artista, Abramovic habla tanto de sí misma como de su propia obra.

Como ya revisamos distintas alternativas de la complicidad se hace evidente (sobre todo en las primeras) que no es necesario que el público se involucre respondiendo o disponiendo su cuerpo y voz para que la obra escénica genere complicidad. Dejando a un lado la complicidad primaria, podemos proponer a modo de aclaración que no toda complicidad genera la interacción activa por parte del público, pero sí toda interacción genera complicidad.

Por otro lado, las complicidades que se pueden lograr en la escena son a partir y en contra de la complicidad primaria fundamental; es decir, sin reunión de cuerpos que actúan y cuerpos voyeurs las otras complicidades no pueden existir debido a que sin 
reunión no hay teatro, y cuando existen (o mejor dicho, se las deja existir) se revelan interrumpiéndola para desatar sus propias estrategias, creando fisuras ficcionales y muestras poco sutiles de realidad.

Así, creemos en una búsqueda donde las complicidades alternativas funcionen como lógicas de un dispositivo, en la incursión en el arte relacional desde el teatro, en modificaciones en cuanto a las convenciones entre espectador y escena a través del dispositivo teatral, en ficciones interrumpidas, en teatro que se denuncia a sí mismo, en expectación dramática. Creemos en las posibilidades compositivas que elegimos perseguir en la teoría y que nos persiguen en la práctica (a veces también viceversa). 


\section{Q Bibliografía}

» Belvis, E. - Sánchez, J. (2015). No hay más poesía que la acción. México, D.F.: Paso de gato.

"Bourriaud, N. (2006). Estética relacional. Buenos Aires: Adriana Hidalgo.

》Boal, A. (2001). Juegos para actores y no actores. Barcelona: Alba.

»Carmona, J. (2010). La poesía clasista. California: Windmills.

»Cornago, Ó. (2015). Ensayos de teoría sobre teatralidad, público y democracia. Madrid.: Abada Editores.

»Dubatti, J. (2011). Introducción a los estudios teatrales. México: Libros de Godot.

» Groys, B. (2014). Volverse público. Las transformaciones del arte en el ágora contemporánea. Buenos Aires: Caja Negra.

» Naugrette, C. (2004). Estética del teatro. Buenos Aires: Ediciones Artes del Sur.

» Oliveras, E. (2013). Cuestiones de arte contemporáneo. Buenos Aires: Emecé.

" Pavis, P. (1988). Diccionario del teatro. Dramaturgia, estética, semiología. Combinado Poligráfico Evelio Rodríguez Curbelo.

» Ranciere, J. (2010). El espectador emancipado. Buenos Aires: Manantial.

»Ubersfeld, A. (2002). Diccionario de términos claves del análisis teatral. Buenos Aires: Galerna. 